\title{
The Characterisation of Mathilde in the Ideational Metafunction of Guy Demaupassant's The Necklace: A Monogeneric Corpus- Based Analysis
}

\author{
Humphrey M. Kapau ${ }^{1}$, Cheela F.K. Chilala ${ }^{2}$, John Simwinga ${ }^{2^{*}}$ \\ ${ }^{1}$ University of the Western Cape, South Africa \\ ${ }^{2}$ The University of Zambia, Zambia
}

*Corresponding Author: John Simwinga, The University of Zambia, Zambia

\begin{abstract}
This study drew upon the theoretical frontiers of Systemic Functional Linguistics (SFL); the literary notion of characterisation; and the methodological locale of Corpus Linguistics (CL) to study the characterisation of Mathilde in the ideational metafunction of Maupassant's The Necklace. Drawing from Halliday's (1966) theorisation of SFL and DiYanni's (2002) conceptualisation of characterisation, the study has examined characterisation in a naturally occurring text titled The Necklace by use of a methodological backbone of CL methodology as espoused by Wu (2009). The corpus involved a single text hence the study was a monogeneric corpus-based study. Within the CL methodology, the ontological and epistemological dimensions of research were kept in check by the positivist and constructivist paradigms, thereby foregrounding a quantitative and qualitative approach to the study, respectively. Based on the nature of the objectives, a descriptive research design was used within which the qualitative and quantitative approaches were utilised. Content analysis was used as a method in analysing data obtained qualitatively while descriptive statistics was utilised in the analysis of data obtained quantitatively. Data collection and analysis drew on Wu (2009) and proceeded as follows: having read the story several times and understood it, the corpus was fed into the UAM Corpus Tool for semi-automated annotation. Frequency lists were then produced to categorise clauses into process-types. Thereafter, lexical and grammatical patterns associated with Mathilde were extracted. This was followed by the manual analysis of the data in accordance to Halliday (1971) in order to explore the characterisation of Mathilde. The findings have revealed that Mathilde is accorded material, mental, relational and verbal processes but denied behavioural and existential processes. The study further established that Mathilde is attributed transitivity patterns in process-types whose statistical distribution and placement in transitivity is deliberately chosen to characterise heras adesperate, materialistic, ungrateful, poor, fast-aging, lazy-turned-hardworking housewife, flamboyant and fantacist character.The study concludes that Mathilde is deliberately accorded some process-types whose statistical distribution characterises her in a different way from the other characters she appears with in the narrative.
\end{abstract}

Keywords: The Necklace, Mathilde, Characterisation, Systemic Functional Linguistics (SFL), Monogeneric, CL methodology

\section{BACKGROUND}

Though distinct fields, linguistics and literature share an interface through stylistics - the study of language in literature that seeks to account for the interpretative effects of a text through an examination of a text's linguistic detail (Halliday, 1967; and Simpson, 2004).One of the theories that has gained momentum in exploring the art of language in a literary text is Systemic Functional Linguistics (henceforth SFL). Developed by Halliday (1966), SFL argues that language is a resource for meaning making and is hierarchically organised into strata which are related to realisation. This hierarchical arrangement of language - called stratification - consists of four strata, namely, context, semantics, lexico grammar and phonology/graphology (Martin and Rose, 2003; Eggins, 2004; and Halliday and Webster, 2009). The strata build from the most abstract (the stratum of phonology/graphology) to the most concrete stratum of context, with the lexicogrammar and semantics strata being in-between. In SFL theorisation, language is seen as resource for making meaning and any text, such as Maupassant's The Necklace, is seen as an instance (technically called the instantiate) for conveying meaning. Thus, SFL looks at language as a system that performs some 
function.In conveying meaning, a text is said to be simultaneously performing three metafunctions of language, notably, the ideational, interpersonal and textual metafunctions of meaning. Droga and Humphrey (2002) have theorised that the ideational metafunction of language is that function of language that expresses the clausal experiences and deals with the Field of a text. Caffarel (2006:5) has defined the interpersonal metafunction as a metafunction of language that "supplies information and resources for enacting (i.e. establishing and maintaining) social relations [and deals with the Tenor of a text]." On the other hand, the textual metafunction refers to the functions of language as expressed through the textual systems of a text - the Mode.

Maupassant's The Necklaceis an instance of language use and therefore can be considered for an SFL inquiry into its language use. Sometimes referred to as Madame Bovary in miniature and as La Parure in French, The Necklace is a short story by the French author Guy de Maupassant. The story was published in 1884 and is about a middle-class woman who is not satisfied with her everyday life. The main character, Mathilde, dreams of wealth and affluence but her dreams end in disaster. The story is famous for its twist ending that over turns an entire plot line through a twisted denouement (Edgar and Roberts, 2007). In the plot of The Necklace, Mathilde is a middle-class girl with ambitions to be rich but sadly, she is married to a poor clerk M. Loisel, having been born in a family of clerks herself. Because she is not content with her marital and wealth status, she exists in a world of fantasy that she was meant to be a rich girl. She spends much of her time dreaming about the successful, fancy life with rich men and furniture that she does not have. One day, her husband M. Loisel comes home with an invitation to a fancy ball thrown by M. Georges Ramponneau, the Minister of Education. Mathilde is more worried about what to wear and her lack of jewellery than being thankful that her husband had gone to lengths to just secure the invitation. M. Loisel struggles to buy her wife a dress to wear but Mathilde still asks for 400 francs because she has no jewels. Unable to sustain the financial demands, M. Loisel suggests that Mathilde sees her friend Madame Forestier, a rich woman who eventually lends Mathilde a gorgeous diamond necklace. When the night of the ball arrives, Mathilde receives attention from everyone because of her stunning beauty and she is over joyous by this. On their way back home after avoiding being seen in her shabby coat, Mathilde realises that the diamond necklace is missing. Her husband spends the next day and week looking for the necklace all over the city but it is never found. They visit one store after another in search of a similar necklace until they find one store having an identical necklace at a cost of thirty-six thousand francs. The cost of the new necklace is twice the amount that M. Loisel owns to his name. This forces the couple to get into debt just to raise the money to buy the necklace which they eventually buy and give back to Madame Forestier without telling her what had transpired. However, the financial strain puts the couple into worsened poverty for the next ten years and during this time, Mathilde loses her looks. When Matilde meets Madame Forestier at the Champs Elysees ten years later, she tells Madame Forestier what had happened to her necklace. At that point, Madame Forestier says, "Oh, my poor Mathilde! Mine was an imitation! It was worth five hundred francs at most! ..." (Maupassant, 2007: 5). The current study drew upon DiYanni's (2002) conceptualization of characterisation to examine the characterisation of Mathilde in the narrative of Maupassant's The Necklace through Halliday's (1966) theoretical lens of SFL and Wu's (2009) methodological locale of CL methodology. By exploring characterisation of Mathilde in Maupassant's The Necklace from the angle of SFL and CL methodology, this study added to similar studies (e.g. Halliday, 1971; Iwamoto, 2008) that have explored The Necklace from a similar conceptual, theoretical and methodological perspectives.

\subsection{Statement of the Problem}

From the time of its inception, the transitivity model has been used in a number of studies that have studied literary works. Among the notable studies that have used the transitivity model are those that have examined characterisation and transitivity (e.g. Halliday, 1971; and Kennedy, 1982); studies that have looked at transitivity, point of view and characterisation (e.g. Mwinlaaru, 2012); and the studies that have looked at transitivity, characterisation and ideology through CL methodology (e.g. Muhammad and Banda, 2016). However, no study has looked at the characterisation of Mathilde in Maupassant's The Necklace using SFL and CL methodology. Therefore, an examination of how transitivity patterning impacts on the characterisation of Mathilde, backed by CL methodology, added further knowledge of the role of linguistics in the construction of literary works in general and characterisation in particular. Therefore, the statement of the problem, stated as a question, was: how 
do transitivity patterns enhance the characterisation of Mathilde in The Necklace? By exploring the aforementioned knowledge gap, this study has added further knowledge to works done on transitivity and SFL (e.g. Halliday, 1966; Halliday, 1971; and Muhammad and Banda, 2016).

\subsection{Research Questions}

Arising from the knowledge gap established, the study sought to address the following research questions:

- What process-types are attributed to Mathilde?

- What transitivity patterns are in process-types attributed to Matilde?

- What do the transitivity patterns attributed to Matilde reveal about her character?

\section{LITERATURE REVIEW}

Notable among the studies that have explored SFL, characterisation and transitivity is that of Halliday (1971) which is regarded by many as being among the earliest studies on linguistic enquiry on literary works (Halliday and Webster, 2009; and Mwinlaaru, 2012). Based on Golding's The Inheritors as the sample of the study, Halliday's (1971) study examined the stylistic significance of transitivity patterns in the narrative of the literary work in order to demonstrate the versatility of SFL as a theory in literary enquiry. Halliday (1971) has concluded that the transitivity patterns in process-types divide the narrative structure of Golding's The Inheritors into two: the first division relates to a narrative about the world of the Neanderthal people, their view of the world around them and that of the tribe. The second narrative shift in the story is one that shows a shift in point of view from the perspective of the people to that of the tribe. In the narrative division, Halliday (1971) concludes that as the principal character, Lok is the cause of the narrative division. Like Halliday (1971), this study on Maupassant's The Necklace looked at transitivity patterning in the narrative of the story. However, unlike Halliday (1971) who looked at the shifts in the narrative due to transitivity patterns, this study examined how transitivity patterns in process-types have built the characterisation of Mathilde. By exploring this knowledge gap, the current study has tested the extent to which SFL is stretchable. Furthermore, by using CL methodology in character enquiry, the present study has added further knowledge on methodological options that Halliday (1971) could have explored.

The other study is that of Kennedy (1982) who drew on Halliday's (1971) use of the transitivity model in Goldwin's The Inheritors to explore characterisation in Conrad's The Secret Agent. Kennedy's (1982) study has concluded that Conrad employs two techniques to develop the narrative in his passages: first, he places inanimate entities in the subject position of material clauses and, secondly, he uses a lot of agentless passive constructions "so that the Actors of the material processes in the clause could be suppressed" (Mwinlaaru, 2012:58). This study also focussed on the narrative of a literary work to explore characterisation, just like Kennedy (1982). However, while Kennedy's (1982) study looked at a British literary work, the current looked at The Necklace, a text of French origin. In so doing, the study expanded on our knowledge aboutthe universalityof language use through transitivity. Furthermore, by appealing to CL methodology as a methodological point of departure, this study provided a methodological alternative to that of Kennedy (1982). Such a methodological choice in transitivity analysis shed more light on the compatibility of SFL theory, transitivity model and CL methodology in literary enquiry. In addition, since CL methodology amalgamates numerical and non-numerical data, the use of the UAM Corpus software in CL methodology shed more light on the use of statistics in studies which use transitivity to study characterisation.

In addition to Halliday (1971) and Kennedy (1982) is Mwinlaaru (2012) who has explored characterisation and point of view in Achebe's Anthills of the Savannah. Mwinlaaru (2012) established that five of the six characters, namely, Sam, Beatrice, Ikwe, Elewa, and Agatha are stereotypes of key social actors in post-independence West Africa, and that these stereotype characters create a socio-political ideology background for Achebe. In addition, Mwinlaaru (2012) concluded that through systematic changes in the transitivity patterns that Chris is associated with, Achebe uses transitivity patterns associated with his literary characters to urge the enlightened but "apathetic citizen to rise up and transform his society through struggle" (Mwinlaaru, 2012: 3). Like Mwinlaaru 
(2012), this study appealed to the literary concept of characterisation in addition to Halliday's (1966) SFL theory in order to study how transitivity patterns impact on characterisation. However, while Mwinlaaru (2012) looked at characterisation and point of view, this study focussed only on characterisation. Secondly, while Mwinlaaru (2012) concentrated on an African novel Anthills of the Savannah, this study looked at a French novel titled The Necklace.By looking at a different novel, the current study added to the existing literature done on characterisation using the theoretical lens of SFL. Additionally, while Mwinlaaru used a stylistics methodology, the current study used CL methodology which was monogeneric in nature. By providing a methodological alternative to that of Mwinlaaru (2012), this study added to our knowledge on options that can be used in the study of literary works using SFL and transitivity.

Another notable study on SFL and transitivity is that of Hubbard (2015) whostudied the character of Aurora, a female character in Rushdie's The Moor's Last Sigh. The study aimed at showing how transitivity patterns as lexico-grammatical features are used to emphasise and show that it is Aurora and other women who dominate not only the narrative of the text but also dominate the men. The findings of Hubbard's (2015) study deduced that Aurora is represented more in the actions as compared to Abraham who appears in passive ones through passive participant roles of Carrier, Circumstance and particularly Goal. The study concluded thatwhile men occupy the peripheral of the narrative inRushdie'sThe Moor's Last Sigh, women are at the centre of the novel. Like Hubbard (2015), this study focused on the characterisation of a female character in Maupassant's The Necklace. In this regard, this study fulfilled a crusade of adding to literature done on female characters in SFL studies conducted so far. However, while Hubbard (2015) focussed on gender dominance, this study focussed on highlighting the characterisation of Mathilde in The Necklace without special biasness to gender disparities. In addition, the current study used a software to annotate and analyse its data. Therefore, this study was of benefit to Hubbard (2015) because it not only added more knowledge on characterisation but also on the versatility CL methodology in character enquiry.

Lastly but not the least, Muhammad and Banda (2016) also appealed to SFL's transitivity in their study of Mandela in the Arabic media. They used an eclectic approach that combined SFL, Critical Discourse Analysis (CDA) and CL to explore how Mandela as a character has been portrayed in Arabic media. Their study established that the transitivity manipulation of process-types account for how Mandela is represented in the clause. Muhammad and Banda (2016) further notedthat material processes in which Mandela is the Actor or main Agent are frequently used in the transitivity obtained from Aljazeera Arabic website. Muhammad and Banda's (2016) argued that such transitivity choices involving Mandela came about because discourse structures were deliberately selected "not only for the sentimental reasons, but also to evoke readers' sympathy regarding his wife's infidelities" (Muhammad and Banda, 2016:1). This study is very identical to Muhammad and Banda (2016) on the basis of also using a CL methodology. Like Muhammad and Banda (2016), this study used a software called UAM Corpus Tool in order to explore characterisation. However, while Muhammad and Banda (2016) looked at Mandela, this study looked at Mathilde in Maupassant's The Necklace. In addition, while Muhammad and Banda (2016) used Critical Discourse Analysis in addition to SFL, this study only used SFL. Through the aforementioned differences, the current study was unique to that of Muhammad and Banda (2016).

\section{THEORETICAL AND CONCEPTUAL FRAMEWORKS}

\subsection{Theoretical Framework}

In studying the characterisation of Mathilde in Maupassant's The Necklace, this study applied some aspects of Systemic Functional Linguistics (SFL).The father of SFL is believed to be Halliday though the theory traces its origins to the anthropologist Malinowski. In later years after Halliday, SFL has had followers such as Fawcett, Hassan, Painter, Matthiessen and O'Donnell (O'Donnell, 2012). As a theory, SFL argues that language is a semiotic system that performs some function. As we communicate, we make choices within the system and, therefore, language is a system of choices intended to perform a particular function (see Droga and Humphrey, 2002). Because language is a system, it is stratified through a process called stratification. Stratification refers to the process by which language is hierarchically layered from the abstract to the concrete strata. According to SFL theorists, the most abstract stratum is that of phonology/graphology (which deals with the sound 
systems and writing of a language)while the most concrete stratum is that of context (which deals with the context of culture and context of situation). In-between the phonology/graphology stratum and the stratum of context are lexicogrammar stratum (lexicon-based) and the semantics stratum (meaning-based)(Halliday, 1966; Droga and Humphrey, 2002; Martin and Rose, 2003; and Caffarel, 2006).

Since language function is at the centre of SFL, Halliday (1966) theorises that any use of language is meant to perform three basic functions called the metafunctions of language. Thus, the concept 'metafunctions of language' is central to SFL theorisations. According to Halliday and Hassan (1976) and Halliday and Matthiessen (2004), the metafunctions of language are those functions that language is meant to perform in society, notably, the ideational, interpersonal and textual metafunctions. The ideational metafunction of language interprets, organises and classifies the participants of the discourse by representing how the world is perceived in terms of experiences. It deals with the Field of discourse. The second metafunction, called the interpersonal metafunction, establishes and maintains social relations and deals with the Tenor of discourse. As earlier alluded to, the last metafunction has been termed the 'textual metafunction' and it looks at how language is organised into coherent and meaningful spoken and written texts (see Halliday, 1971; Halliday, 1978; Fowler, 1986; Droga and Humphrey, 2002; Caffarel, 2006; and Halliday and Webster, 2009).

Of the three metafunctions of language theorised by Halliday (1966), this study focussed on the ideational metafunction. In the ideational metafunction, Halliday (1966) developed the grammar of the clause that he called transitivity. The current study used the transitivity model to analyse the characterisation of Mathilde in Maupassant's The Necklace. According to Droga and Humphrey (2002), Halliday and Webster (2009) and Mwinlaaru (2012), the transitivity model is a model to language that looks at how clausal experience is construed through the grammar of the clause.

In the ideational metafunction to language, this study appealed to the notion of transitivity. In paraphrasing Halliday (1971), Mwinlaaru (2012:21) observes that transitivity is a "syntacticosemantic concept which refers to the manner in which a writer or speaker represents, at clausal level of language, his experience of the real world or his own world of consciousness." Going by the aforementioned, transitivity is seen as a grammatical way of modelling the description of the content of the clause. In transitivity, the clause is said to be made up of three components, namely, the Process, the Participant and the Circumstance. According to Halliday (1966), the Process is the centre of the experiential mode of the clause. It is traditionally realised by the verb phrase (e.g. walked). The Participant of the clause refers to participants directly involved in the Process and is usually realised by noun phrases (e.g. the man). The Circumstance is the third component of the clause in SFL transitivity, and refers to the adjunct element of the clause structure. As a grammatical component in transitivity, the Circumstance is realised by prepositional and adverb phrases (e.g. to the market and very quickly). It is worth noting that the Circumstance comprises a wide range of semantic class, notably, Extent, Location, Manner, Cause, Contingency, Accompaniment, Role, Matter and Angle, as well as their sub-categories which carry a subcategory probe (Halliday, 1966; Droga and Humphrey, 2002; Simpson, 2004; Halliday and Matthiessen, 2004; Iwamoto, 2008; and Mwinlaaru, 2012).

Based on the Process in transitivity, Halliday (1966) has classified the grammar of the clause into six process-types. These are processes of action and doing (material processes - MaPs); processes of cognition, feeling and affection (mental processes - MePs); processes of having and being (relational processes - RePs); processes of saying and telling (verbal processes - VePs); processes of physiological and psychological nature (behavioural processes - BePs); and processes of existing (existential processes - ExPs). According to Iwamoto (2008) and Droga and Humphrey (2002), MaPs are processes of 'doing' and 'happening' in the physical world and have two inherently key participants, an obligatory element called the Actor and an optional element called the Goal. An additional third element called the Circumstance is also often times found in MaPs and it provides additional information on the When, Whereand Howof the process (Halliday, 1966; Droga and Humphrey, 2002; Martin and Rose, 2003; Iwamoto, 2008; and Mwinlaaru, 2012).

While MaPs deal with 'goings-on' in the physical world, MePs deal with internalised processes that encode the meanings of feeling, thinking and perception(Simpson, 2004; and Martin and Rose, 2003). Grammatically, all MePs involve two inherent participants namely the Sensor and the Phenomenon. 
What is termed 'Phenomenon' is that which is felt, thought or perceived by the conscious Sensor. The Sensor is that which feels, thinks or perceives the Phenomenon(Eggins, 1994:242-3; Halliday, 1994:117).

RePs are the third type of process-types and, according to Eggins, (1994); Halliday and Matthiessen (2004); Simpson (2004); and Iwamoto (2008), RePs are processes of being and having and are probably the most detailed of all process-types RePs are divided into intensive, possessive and circumstantial RePs. Intensive RePs are RePs that use intensive verbs (e.g. is). On the other hand, possessive RePs use verbs of possession (e.g. has) while circumstantial RePs use verbs that indicate circumstantial relations (e.g. $i s$ at). Therefore, intensive RePs establish a relationship of ' $\mathrm{X}$ is $\mathrm{Y}$ ' connection between two elements; possessive RePs create an ' $\mathrm{X}$ has $\mathrm{Y}$ ' relationship; and circumstantial RePs connote an ' $\mathrm{X}$ is at $\mathrm{Y}$ ' relationship. In RePs, the central participants are the Carrier, Attribute, Token and Value.

SFL theorists such as Halliday (1966) and Halliday and Matthiessen (2004) have argued that MaPs, MePs and RePs are the three major process-types while VePs, BePs and ExPs are minor process-types because they are often times incorporated in the three major process-types. VePs are theoretically found at the border of MePs and RePs, and express the relationship between ideas constructed in human consciousness and those enacted in the form of language (Halliday and Matthiessen, 2004; Martin and Rose, 2003). In VePs, the participant speaking is called the Sayer; the addressee to whom the process is directed is termed Target or Recipient; and what is said is called the Verbiage (Droga and Humphrey, 2002). On the other hand, BePs are processes of physiological and psychological behaviour, and can be realised as MaPs or MePs. The main participant in BePs is the Behaver though it is possible to find an optional participant called the Range (Halliday, 1994:107). The sixth processtype (and third minor process-type) is that of ExPs. ExPs are can be realised as either RePs or MaPs. The inherent clause participant in ExPs is the Existent traditionally identified as there (see Halliday, 1966; Droga and Humphrey, 2002; Eggins, 2004; and Halliday and Matthiessen, 2004).

In studying the characterisation of Mathilde in the ideational metafunction of Maupassant's The Necklace, this study used the transitivity model. The application of theory was made possible by subjecting the corpus to a vigorous analysis of process-types in a CL methodology.

\subsection{Conceptualising Characterisation}

The study of Mathilde's character in Maupassant's The Necklace was premised on DiYanni's (2002) conceptualisation of characterisation. According to DiYanni (2002) as paraphrased by Mwinlaaru (2012), characterisation refers to ways by which writers (e.g. Maupassant) present, reveal and develop character in a literary work such that readers are able to make judgements and reinforce their view of the themes of the text. Characterisation is done in a number of ways such as what people say about the character, what the character says and does, a character's attitude and through narratorial voice. By exploring the grammar of the clause through process-types, this study examined the characterisation of Mathilde in Maupassant's The Necklace.

\section{Methodology}

The current study on the characterisation Matilde in Maupassant's The Necklace was framed within the methodological framework of Corpus Linguistics (CL) and was monogeneric because it used one text. According to $\mathrm{Wu}(2009: 138)$, a corpus-based methodology "is a methodology for investigating language and language use, and obtaining quantitative evidence through large quantities of naturally occurring texts - called the corpora." The study was informed by the positivist and constructivist paradigms which in turn tilted the study towards a descriptive research design within qualitative and quantitative approaches were used. Content analysis and descriptive statistics were used as data analysis methods in the qualitative and quantitative approaches respectively(e.g. Kothari, 1985; Brink and Wood, 1988; Kumar, 2005; and Goertzen, 2017).Data collection and analysis was based on Wu (2009) and proceeded as follows: having acquired a soft copy of The Necklace and having read it several times till the researcherswere sure they understood it;the corpus was fed into the UAM Corpus Tool software for grammatical annotationina semi-automated manner. Frequency counts and 
The Characterisation of Mathilde in the Ideational Metafunction of Guy Demaupassant's The Necklace: A Monogeneric Corpus-Based Analysis

grammatical features were extracted and then analysed according to Halliday's (1977) transitivity study.

\section{FINDINGS/DISCUSSION}

\subsection{Process-Types Attributed to Mathilde}

In pursuance of research question one (i.e. What process-types are attributed to Mathilde?), the corpus-based study observed in the grammar of transitivity of Maupassant's The Necklace, Mathilde is allotted processes of action and doing (MaPs); processes of cognition, feeling and perception (MePs); processes of being and having (RePs); and processes of saying and telling (VePs). However, she is denied processes of behaving (BePs) and those of existing (ExPs). The findings further indicated that the statistical distribution of process-types differed not only with Mathilde as an individual character (intra-character comparison) but also among the other characters, namely, $\mathrm{M}$. Loisel; M. Ramponneau; Madame Forestier and the First Jeweler. The findings on process-types attributed to Mathilde are statistically summarised in Table 1 below:

Table1: Process-types attributed to Mathilde in relation to other characters

\begin{tabular}{|l|l|l|l|l|l|l|l|l|}
\hline \multirow{2}{*}{ CHARACTER } & \multicolumn{7}{|c|}{ PROCESS-TYPES } & \multirow{2}{*}{ PER } \\
\cline { 2 - 8 } & MaPs & MePs & \multicolumn{1}{|c|}{ RePs } & \multicolumn{1}{c|}{ VePs } & \multicolumn{1}{c|}{ BePs } & \multicolumn{1}{c|}{ ExPs } & TOTAL & CENT \\
\hline Mathilde & 99 & 40 & 28 & 27 & 0 & 0 & $\mathbf{1 9 4}$ & $\mathbf{4 9 \%}$ \\
\hline M. Loisel & 81 & 7 & 9 & 21 & 0 & 0 & $\mathbf{1 1 8}$ & $\mathbf{3 0 \%}$ \\
\hline Madame Forestier & 24 & 3 & 9 & 8 & 0 & 0 & $\mathbf{4 4}$ & $\mathbf{1 1 \%}$ \\
\hline M. Ramponneau & 8 & 0 & 3 & 0 & 0 & 0 & $\mathbf{1 1}$ & $\mathbf{3 \%}$ \\
\hline The First Jeweler & 4 & 1 & 1 & 2 & 0 & 0 & $\mathbf{8}$ & $\mathbf{2 \%}$ \\
\hline Others & 10 & 2 & 3 & 4 & 2 & 0 & $\mathbf{2 1}$ & $\mathbf{5 \%}$ \\
\hline TOTAL & $\mathbf{2 2 6}$ & $\mathbf{5 3}$ & $\mathbf{5 3}$ & $\mathbf{6 2}$ & $\mathbf{2}$ & $\mathbf{0}$ & $\mathbf{3 9 6}$ & $\mathbf{1 0 0 \%}$ \\
\hline PERCENT & $\mathbf{5 7 \%}$ & $\mathbf{1 3 \%}$ & $\mathbf{1 3 \%}$ & $\mathbf{1 6 \%}$ & $\mathbf{1 \%}$ & $\mathbf{0 \%}$ & $\mathbf{1 0 0 \%}$ & \\
\hline
\end{tabular}

As Table 1 indicates, Mathilde is attributed MaPs, MePs, RePs and VePs but denied BePs and ExPs in the grammar of the clause. It can be further observed from Table 1 that the frequency and percentage distribution of process-types in The Necklace differs from character to character. Out of a total of 396 tokens (100\%), Mathilde is accorded 194 tokens (49\%); M. Loisel is attributed 118 tokens (30\%); Madame Forestier is allotted 44 tokens (11\%); M. Ramponneau is given 11 tokens (3\%); The First Jeweler is assigned 8 tokens (2\%); and the other characters are apportioned 21 tokens (5\%). The findings further found that like other characters, Mathilde dominates in MaPs (99 tokens) as part of the total of 226 tokens (57\%). Table 1 also shows that Mathilde is represented more in processes of doing and action (MaPs) and those of cognition, perception and affection (28 tokens) while her RePs (28 tokens) and VePs (927 tokens) almost share an equifrequencyand are both on a lower scale.The aforementioned process-type statistics about Mathilde gives us a hint that the characterisation of Mathilde is mainly achieved through her actions in the physical world (i.e. MaPs) and also through her thoughts, perceptions and affections (i.e. MePs). What she says and tells (i.e. VePs) and what she has and is (i.e. RePs) merely solidify her mental and physical state. The findings on process-types attributed to Mathilde have validated theoretical postulations and observations that in the grammar of the clause, writers of literary works make choices within the system of language they use in order to achieve clausal experience (e.g. Halliday, 1966; Halliday, 1971;Droga and Humphrey, 2002; Martin and Rose, 2003; and Halliday and Matthiessen, 2004; Mwinlaaru, 2012: and Muhammad and Banda, 2012). A further implication arising from the findings on process-types attributed to Mathilde is that process-types are the fundamental transitivity feature that shape the theoretical fabric of the ideational metafunction (e.g. Martin and Rose, 2003; Caffarel, 2006; and Halliday and Webster, 2009). From the perspective of CL methodology, the statistical evidence on process-types re-affirm the indisputable role of CL methodology in literary and linguistic enquiry (e.g. Kothari, 1985; Brink and Wood, 1988; Kumar, 2005; and Wu, 2009).

\subsection{Transitivity Patterns and the Characterisation of Mathilde in The Necklace}

The findings on research question two (i.e. What transitivity patterns are in process-types attributed to Mathilde) and research question three (i.e. What do the transitivity patterns attributed to Mathilde 
reveal about his character?) were that Mathilde is apportioned a number of transitivity patterns in process-types which help in her characterisation. Below are the transitivity patterns which were identified in process-types and what they reveal about Mathilde's characterisation:

\subsubsection{Dominance of Maps Attributed to Mathilde as Compared to Other Characters}

According to the findings, Mathilde is accorded more MaPs than any other character and this strategy is used to characterise her as a materialistic and ungrateful character.By allotting a higher frequency of MaPs (99 tokens, 49\%) to Mathilde than to any other character, she is cast as a woman who is after materialistic things and who is never content with her state. She suffers from what we wish to coin, herein, as The Mathilde Complex - a complex of unending desire for things such that one lives beyond his or her means and forgets to appreciate his or her present state of being. In the context of The Necklace, what we have termedTheMathilde Complex refers to a special form of materialistic greedy that makes someone live beyond their means, while continuously being unappreciative of their present conditions. Mathilde is trapped in her own pursuit for material things, forgetting who she is and how fortunate her situation is. The statistical dominance of MaPs attributed to Mathilde as compared to other characters is shown in Figure 1 below:

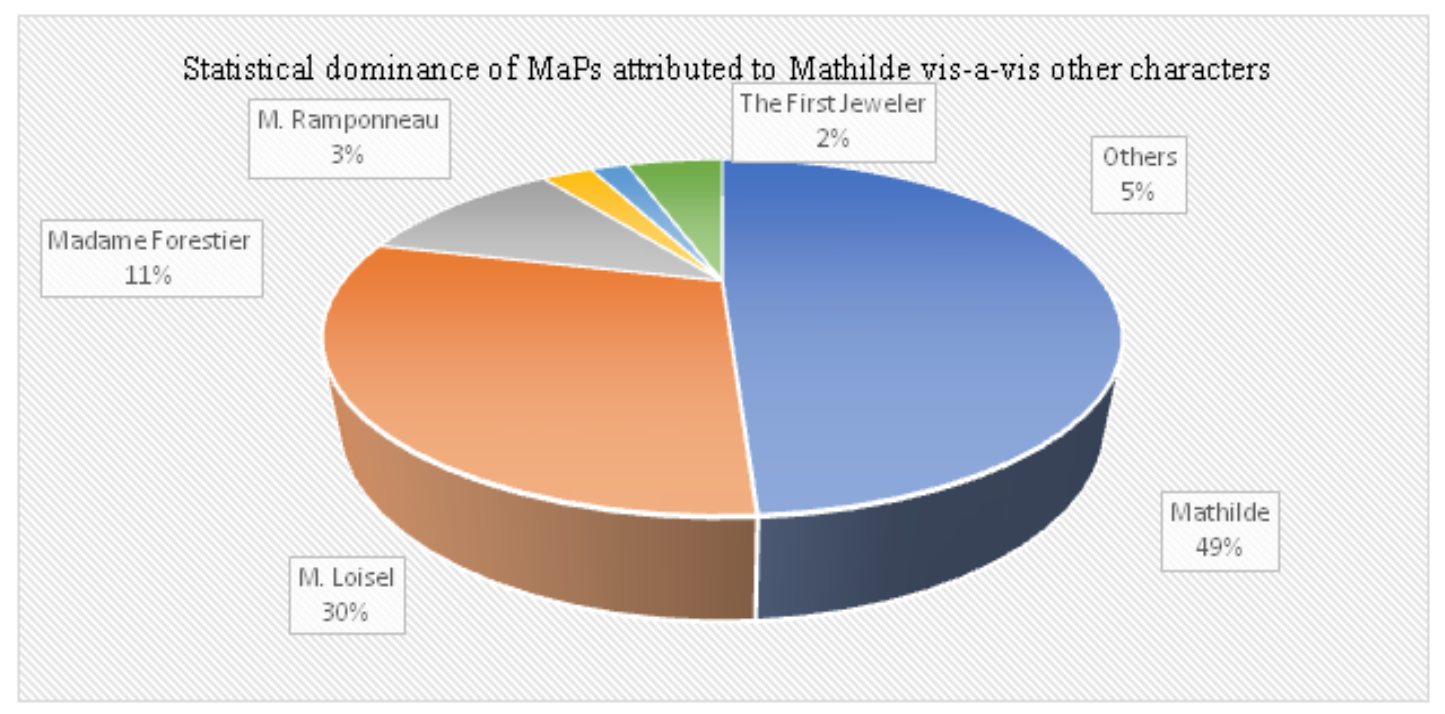

Figure1: Dominance of MaPs attributed to Mathilde as compared to other characters

As Figure 1 indicates, Mathilde is accorded 49\% MaPs and her runners-up is her own husband $\mathrm{M}$. Loisel who is attributed 30\% MaPs. In the context of the story, M. Loisel is only an appeaser of Mathilde's materialistic desires for he struggles to make ends meet just to make his wife Mathilde happy. It is also through a sharp contrast between Mathilde and other characters in the story that Maupassant further projects Mathilde as materialistic and ungrateful. The percentage differential in MaPs between Mathilde (49\%) and other characters such as the first jeweler (2\%) further shows how distant Mathilde's lifestyle is from reality. While the first jeweler, M. Ramponneau, Madame Forestier and M. Loisel are content with their life, Mathilde is not.The statistical findings on MaPs validate the SFL theorisation that in a system and system network of the clause, writers manipulate the statistical profile of linguistic choices in order to achieve specific goals of their literary works (e.g. Wu, 2009; and Halliday and Webster, 2009). In the context of MaPs in Maupassant's The Necklace, statistics is used to project the theme of wealth and suffering through the characterisation of Matilde as a materialistic and ungrateful character.

\subsubsection{Strategic Distribution of MaPs Attributed to Mathilde}

Although the dominance of MaPs shows Matilda as materialistic and ungrateful because of her being more concerned about physical things, their strategic placement and grammatical content in some sections of the story helps characterise Mathilde as a poor, fast-aging housewifeand lazy-turnedhardworking housewife. At the beginning of the story, Mathilde is inscribed mostly in processes of cognition, perception and affection (MePs) for she mostly dreams about silent antechambers, Oriental tapestries, vast living rooms and "elegant furniture loaded with priceless ornaments, and inviting 
smaller rooms, perfumed, made for afternoon chats with close friends - famous, sought after men, who all women envy and desire" (Maupassant, 2007:1). At this stage of the narrative, Mathilde only loves dreaming such that even "[the] sight of the little Brenton girl who did her housework filled her with terrible regrets and hopeless fantasies" (Maupassant, 1984:1). However, towards the end of the story after Mathilde loses Madame Forestier's necklace, Maupassant stylistically increases the frequency of Actor role for Matilde while ensuring that things involving house chores constitutes most of her Goals and Circumstances. This is specially tailored in the narrative to characterise Matilde as a poor, fast-aging and lazy-turned-hardworking housewife. The aforementioned observations are illustrated in (1) - (3) below:

She washed the dishes, Actor Process Goal

staining her rosy nails on greasy pots and the bottoms of pans.

\begin{tabular}{|l||c|}
\hline \multicolumn{2}{|c|}{ Circumstance } \\
\hline Process & Goal \\
\hline
\end{tabular}

(2)

She washed the dirty linen, the shirts and the dishcloths,
Actor Process Goal

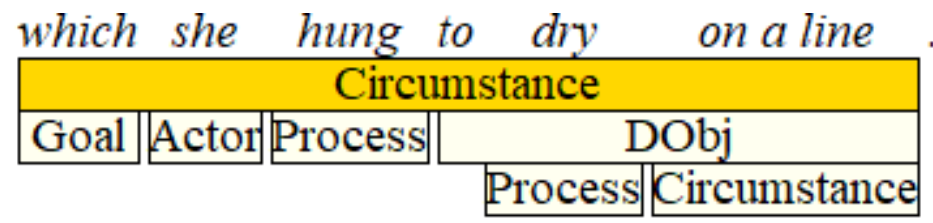

\begin{tabular}{|c|c|c|c|}
\hline \multicolumn{4}{|c|}{ Element/Clause } \\
\hline \begin{tabular}{|l||} 
Actorocess \\
\end{tabular} & Goal & Recipient & Circumstance \\
\hline
\end{tabular}

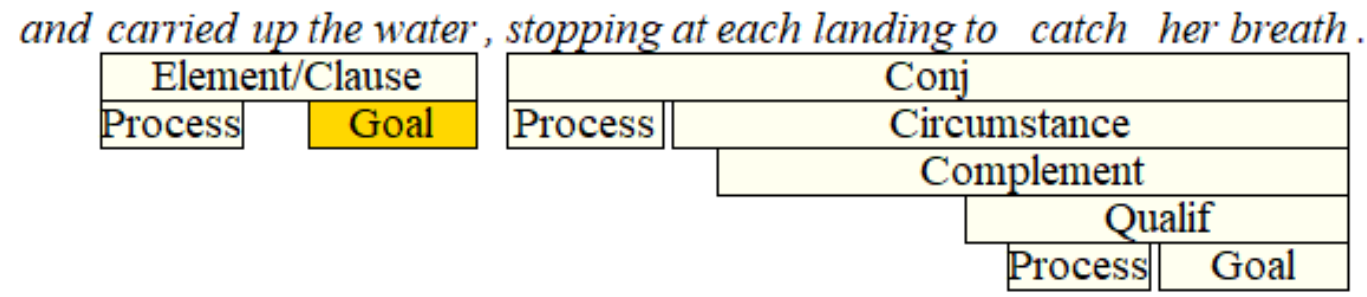

In (1) - (3), Matilde is the Actor identified as She while her constellation of Processes in MaPs include washed; staining; washed; hang; carried; and carried. Her actions indicate that she is no longer the special breed of women that never does dirty work in a homestead. She now does the works that her retrenched Breton maid used to in the house. In (1), the Goal of her actions are the dishes such that she even stains her rosynails.Nails are the pride of a woman and when they are stained due to work, it indicates that one is less caring about their feminine pride. This shows Mathilde as now humble. In (2), the Goals of Mathilde's actions are the dirty linen, the shirts and the dishclothswhile in (3), the Goals are the garbage and the water.By focussing on Goals which associated with the kitchen and daily duties of a poorly married woman, Maupassant carves the Matilda's character as one that transforms from that being fantasist to one that underscores the reality of her poverty and her becoming hardworking as a result. This is further strengthened by the grammatical component of 
Circumstances associated with clauses in (1) - (3), such as, on greasy pots and the bottoms of pans \{Circumstance of Location: spatial: where?\};on a line \{Circumstance of Location: spatial: where ; and every morning \{Circumstance Extent: temporal: for how long\}.The Circumstance show a state of endurance and growth from illusion to reality in the character of Mathilde. Through such a careful stylistic distribution of MaPs in The Necklace, Maupassant skillfull characterises Mathilde as a poor, fast-aging housewife and a lazy-turned-hardworking housewife. Through Mathilde's transformative character, the themes of pride and poverty are addressed, for, as DiYanni (2002) notes, one purpose of characterisation is to help put together the thematic concerns of a literary work. When Mathilde stops day dreaming about wealth, she comes to realise that her worst fears have become true and that she was better than she was before borrowing the necklace.

\subsubsection{Strategic use of Mathilde as a Sensor Insome Mental Processes}

Another transitivity pattern that Maupassant uses is that of strategically making Mathilde the Sensor in some MePs. Through this transitivity patterns, Mathilde is characterised asflamboyant,ungrateful and afantacist.This is illustrated in (4) - (6) below:

(4)

\section{She suffered endlessly, Senser Process Circumstance}

feeling she was entitled to all the delicacies and luxuries of life.

\begin{tabular}{|c|c|c|}
\hline \multicolumn{3}{|c|}{ Phenomenon } \\
\hline Process & & \\
\hline & Process & Circumstance \\
\hline
\end{tabular}

(5)

\begin{tabular}{|c|c|}
\hline Senser Process & Circumstance \\
\hline she & looked at the dirty walls, \\
\hline \multicolumn{2}{|c|}{ Circumstance } \\
\hline \multicolumn{2}{|c|}{ Actor/Sensor Process } \\
\hline \multicolumn{2}{|c|}{ the worn-out chairs and the ugly curtains } \\
\hline \multicolumn{2}{|c|}{ Circumstance (Continued...) } \\
\hline Circumst & \\
\hline
\end{tabular}

(6)

She dreamed of silent antechambers hung with Oriental tapestries
Process
\begin{tabular}{c|c|} 
Circumstance \\
Complement \\
\cline { 2 - 2 }
\end{tabular}

In (4), Mathilde is a Sensor whose Phenomenon is she was entitled to all the delicacies and luxuries of life while her Process in (4) and (5) is suffered \{mental process: affection \}. The reasons for her sufferings are expressed through the Circumstance component of the clause. In (4), she feels she is suffering because she is entitled to all the delicacies and luxuries of life \{Circumstance of Matter: what about $\}$ while in (5), Mathilde feels she is suffering because of the poorness of her house \{Circumstance of Cause: reason: why?\}; and as she looked at the dirty, the worn-out chairs and the ugly curtains \{Circumstance of Contingency: condition: under what conditions?\}.At this stage of the narrative, Mathilde is in her own world, overtaken by what we are calling the Mathilde Complex for 
she is a fantasist, hence flamboyant and unappreciative of her current conditions. Because Mathilde is trapped in internalised processes of affection, cognition and perception, her view of the world is unreal and because of this, she presents a fake mask to the world. She is flamboyant and ungrateful and the aforementioned character traits in her stem from her mental processes of cognition in (6) where she fantasises of silent antechambers hung with Oriental tapestries \{Circumstance of Matter: what about?\}.Thematically, the flamboyant, ungrateful and fantasist character of Mathilde helps uphold the themes of wealth, pride and suffering in Maupassant'sThe Necklace.

\subsubsection{Use of Intensive and Possessive Reps}

In processes of being and having (RePs), Maupassant uses intensive and possessive RePs in order to characterise her as poor, desperate and ungrateful. This is shown in (7) below:

\begin{tabular}{|c|c|c|c|}
\hline She & was & of those pretty and charming girls & born \\
\hline \multirow{3}{*}{ Carrier } & Process Attribute & Circumstance & \\
\hline & & Complement & \\
\hline & & & $\frac{\text { Qualif }}{\text { Process }}$ \\
\hline
\end{tabular}

as if by an error of fate, into a family of clerks. Circumstance

(8)

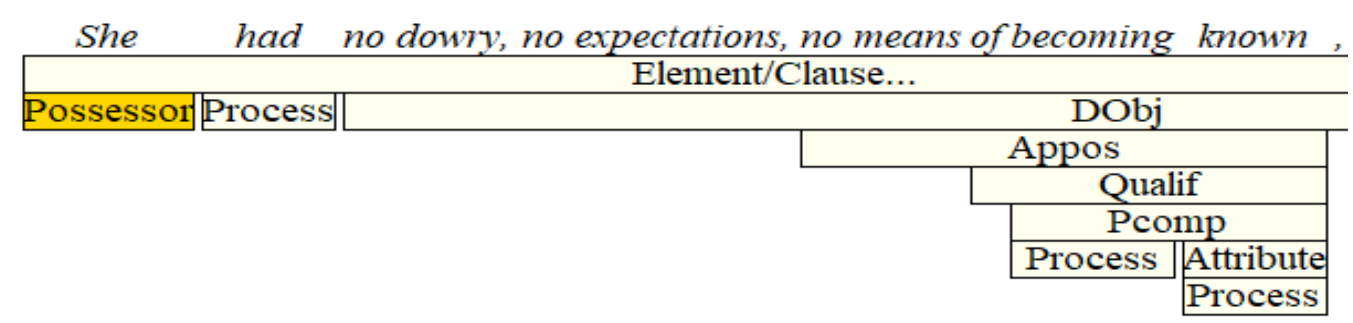

understood, loved or wedded by a man of wealth and distinction;

\begin{tabular}{|c|c|c|c|}
\hline \multicolumn{3}{|c|}{ Element/Clause (Continued...) } & \\
\hline & & & Circumstance \\
\hline \multicolumn{3}{|c|}{ Qualif } & \\
\hline Element & Element & Element & \\
\hline Process & Conj & Process & \\
\hline
\end{tabular}

In (7), Mathilde is a Carrier identified as She and she is identified as being one of those pretty and charming girls born, as if by an error of fate, into a family of clerks. Example (7) shows that although Mathilde has good looks, it is unfortunate that she finds herself born from a family of clerks symbolising the lowly. She is poor and comes from a poor family. In (8), Mathilde is the Possessor who (had)no dowry; (had) no expectations; (had) no means of becoming known; (had no means of being)] understood; (had no means of being) loved; or (had no means of being) of being wedded by no other than a man of wealth and distinction \{Circumstance of Manner: means: by what means?\}. This shows that apart from being poor, Mathilde is not happy with her marriage because she was even married off without dowry. She is a nobody. For this, she is desperate to find ways of being known to the world. She lives in self-denial, making her desperate for recognition and ending up being ungrateful. Mathilde is an example of females who regard their femininity to be measured by fame, presence of dowry, wealth and pride. For this, she is desperate to make it in life.

\subsubsection{Use of Quoted Verbiage in Verbal Processes}

The last transitivity pattern prominent in the narrative of Maupassant's The Necklace relates to the use of Quoted Verbiage. Although Reported Verbiage exists in the narrative, the Quoted Verbiage plays a prominent role in characterising Mathilde and other characters in story.The findings revealed that 
through Quoted Verbiage in VePs, Mathilde is characterised as a materialistic and ungrateful character. For example, when one evening her husband brings home an invitation to a ball to be hosted by the Minister of Education, M. Ramponneau, instead of Mathilde being happy about it, she is more concerned about what she will wear that day. Her response is shown in (9) below:

"Give your invitation to a friend whose wife has
\begin{tabular}{|l|r|r}
\hline Quoted Verbiage.... & Recipient \\
\hline Process & Goal & Complement \\
\hline & & Qualif \\
\cline { 2 - 3 } & Possessor & Process \\
\hline
\end{tabular}

\begin{tabular}{|c|c|c|}
\hline better clothes & than & "SHE \\
\hline \multicolumn{2}{|c|}{ Quoted Verbiage (Continued) } & \multirow{3}{*}{ Sayen Process } \\
\hline Recipient (Continued...) & Circumstance & \\
\hline $\begin{array}{l}\text { Complement (Continued...) } \\
\text { Qualif (Continued...) }\end{array}$ & Actor Process & \\
\hline
\end{tabular}

In (9), the Sayer is Mathilde and her Quoted Verbiage is a reaction to the invitation card from the Minister of Education. The Target of the Quoted Verbiage is her husband M. Loisel. One would expect Mathilde to be joyful but instead, she changes the focus of the topic from the invitation card to how she lacks that which other people's wives have - clothes. Ironically, a materialistic thing in the form of a high-profile invitation letter gives rise to another materialistic need (i.e. clothes). Although the circle of needs s endless for every human, contentment is key. By complaining when she was supposed to be happy, Mathilde's character is shown as one which is ungrateful and materialistic. Even when her husband buys her a dress, she is now worried about jewellery and ends up borrowing a necklace that costs their fortune.

\section{CONCLUSION}

Coming this far, it can be concluded that the narrative of Maupassant's The Necklace is shaped by process-types. In addition, the process-types have transitivity patterns which have a bearing on the characterisation of Mathilde and other characters. The findings we have brought forth in this study validate the theoretical observation that process-types form the ideational meaning of language (e.g. Martin and Rose, 2003; Caffarel, 2006; and Halliday and Webster, 2009). The findings also confirm earlier studies which have concluded that each narrative is potentially unique in terms of processtypes, transitivity patterns and their impact on characterisation (e.g. Halliday, 1971; DiYanni, 2002; Mwinlaaru, 2012; and Muhammad and Banda, 2016). From the perspective of CL methodology, the varying statistics in process-typesand transitivity patterns as computed by the UAM Corpus Toolvalidates the significance of numerical data in establishing the significance of process-types in a text and the methodological versatility of CL methodology (e.g. Kothari, 1985; Brink and Wood, 1988; Kumar, 2005; Wu, 2009; and Goertzen, 2017).

\section{REFERENCES}

[1] Brink, J. B. \&Wood, M. J.(1998)Advanced Designs in Nursing Research. 2nd Edition. Thousand Oaks: Sage.

[2] Caffarel, A. (2006) A systemic functional grammar of French: From grammar to discourse. London: Continuum.

[3] DiYanni, R. (2002) Literature: Reading fiction, poetry and drama (5th ed.). New York: McGraw-Hill.

[4] Droga, L. \& Humphrey, S. (2002) Getting Started with Functional Grammar. Sydney: Routledge.

[5] Edgar, V.R. \& Jacobs, H.E. (2007) Literature: And Introduction to Reading and Writing. Upper Saddle River: Prentice Hall.

[6] Eggins, S. (1994) An Introduction to Systemic Functional Linguistics. London: Pinter Publisher.

[7] Eggins, S. (2004) An introduction to systemic functional linguistics. $2^{\text {nd }}$ Ed. New York: Continuum. 
The Characterisation of Mathilde in the Ideational Metafunction of Guy Demaupassant's The Necklace: A Monogeneric Corpus-Based Analysis

[8] Fowler, R. (1986) Linguistic criticism. Oxford: Oxford University Press.

[9] Goertzen, M. J. (2017) "Introduction to Quantitative Research and Data". Library Technology Reports. 53 (4): $12-18$.

[10] Halliday, M. A. K. (1966) Some notes on 'deep' grammar. Journal of Linguistics, 2 (1), 57-67.

[11] Halliday, M.A.K. (1970) "The place of 'Functional Sentence Perspective' in the system of linguistic description”. Paper read at the International Symposium on FSP, Marianske Lazne, Oct. 1970.

[12] Halliday, M. A. K. (1971) Linguistic Function and Literary Style: An Inquiry into the Language of William Golding's The Inheritors. In S. Chatman (Ed.), Literary style: A symposium (pp. 330-368). New York: Oxford University Press.

[13] Halliday, M. A. K. \& Hassan, R. (1976) Cohesion in English. London: Longman.

[14] Halliday, M.A.K. (1978)Language as social semiotic. The Social Interpretation of Language and Meaning. London: Edward Arnold.

[15] Halliday, M. A. K. (1994) An introduction to functional grammar (2nd ed.). London: Hodder Arnold.

[16] Halliday, M. A. K. \& Matthiessen, C. M. I. M. (2004) An introduction to functional grammar (3rd ed.). London: Hodder Arnold.

[17] Halliday, M.A.K. \& Webster, J.J. (2009) Continuum companion to systemic functional linguistics. (Ed). London: Continuum International Publishing Group.

[18] Hubbard, H.E. (2015) Love, War and Lexicogrammar: Transitivity and Characterisation in Salman Rushdie's 'The Moor's Last Laugh'. MA Thesis, University of South Africa (UNISA).

[19] Iwamoto, N. (2008) Stylistic and Linguistic Analysis of a Literary Text using Systemic Functional Grammar. Retrieved May, 2018 from:http://human.kanagawau.ac.jp/gakkai/publ/pdf/no162/16209.pdf at $10: 33 \mathrm{pm}$.

[20] Kennedy, C. (1982) Systemic grammar and its use in literary analysis. In R. Carter (Ed.), Language and literature: An introductory reader in stylistics. London: George Allen and Unwin.82-99

[21] Kothari, C.R. (1985) Research Methodology-Methods and Techniques. New Delhi, Wiley Eastern Limited.

[22] Kumar, R. (2005) Research Methodology-A Step-by-Step Guide for Beginners, (2nd.ed). Singapore: Pearson Education.

[23] Martin, J.R. (1997) 'Analysing genre: functional parameters. In F. Christie and J.R. Martin (eds.) Genres and Institutions: Social Processes in the Workplace and School. London: Cassell; 3-39.

[24] Martin, J.R. and Rose, D. (2003) Working with discourse: Meaning beyond the clause. London: Continuum.

[25] Muhammad, T. and Banda, F. (2016) Mandela in the Arabic Media: A Transitivity Analysis

[26] Maupassant, Guy de (2007) The Necklace. In Edgar, V.R. \& Jacobs, H.E. (Ed.) Literature: And Introduction to Reading and Writing. Upper Saddle River: Prentice Hall. 45-47

[27] Mwinlaaru, I. (2012) 'A Stylistic Study of Characterisation and Point of View in Chinua Achebe's Anthills of The Savannah: A Functional-Semantic Perspective.' MA Dissertation, University of Cape Coast.

[28] O'Donnell, M. (2008) "Demonstration of the UAM Corpus Tool for text and image annotation". Proceedings of the ACL-08: HLT Demo Session (Companion Volume), Columbus, Ohio, June 2008. Association for Computational Linguistics. pages 13-16.

[29] O'Donnell, M. (2017) "Interactions between Natural Language Processing and Systemic Functional Linguistics". In Bartlett, T. and O'Grady, G. (eds) The Routledge Handbook of Systemic Functional Linguistics. Routledge.

[30] Simpson, P. (2004) Stylistics: A resource book for students. London \& New York: Routledge.

[31] Wu, Canzhong (2009) 'Corpus-Based Research'. Continuum companion to systemic functional linguistics. Halliday, M.A.K. \& Webster, J.J. (ed.). London: Continuum International Publishing Group.

[32] https://www.shmoop.com/the-necklace-maupassant/summary.html

Citation: Humphrey M. Kapau, Cheela F.K. Chilala, John Simwinga. The Characterisation of Mathilde in the Ideational Metafunction of Guy Demaupassant's The Necklace: A Monogeneric Corpus-Based Analysis. "International Journal on Studies in English Language and Literature (IJSELL), vol 7, no.76, 2019, pp. 24-36. doi: http://dx.doi.org/ 10.20431/2347-3134. 0707004.

Copyright: (C) 2019 Authors. This is an open-access article distributed under the terms of the Creative Commons Attribution License, which permits unrestricted use, distribution, and reproduction in any medium, provided the original author and source are credited. 